\title{
¿ES REINSERCIÓN SOCIAL O INSERCIÓN SOCIAL LO QUE NUESTRA NIÑEZ Y ADOLESCENCIA NECESITA?
}

\section{Hilda Rodríguez de Casoverde*}

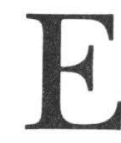

1 concepto y contenidos de Reinserción/Inserción Social en la sociedad salvadoreña, aun no hace eco en todos los sectores de la población, a pesar del acelerado incremento de niños, niñas y jóvenes que por circunstancias diversas han caldo en la marginación por la carencia de programas orientados a la prevención de la cascada de efectos y consecuencias que arrastra cada uno de los problemas sociales que afecta a toda Latinoamérica, especialmente en El Salvador, razón por la cual las instancias comprometidas con el tema niñez y adolescencia conscientes del reto que este fenómeno social significa para cada uno de éstas, hacen esfuerzos por unificar criterios y coordinar acciones, a iniciativa del Programa Interinstitucional "Hacia un Sistema de Justicia Juvenil”, conformándose un subcomité de Reinserción Social constituido por: dos miembros del Juzgado de Ejecución de Medidas de Santa Ana; tres miembros del Juzgado de Menores de San Salvador, una miembro del Instituto Salvadoreño de Protección al Menor (ISPM); dos miembros de la Policía Nacional Civil y tres miembros del Programa Interinstitucional UTE.

El propósito principal de este subcomité es establecer conceptos y contenidos a fin de crear procesos sistematizados de Reinserción/ Inserción Social, que permitan al niña y adolescente en riesgo y en

\footnotetext{
* Coordinadora Programa Reinserción Social, División Institucionalizada, Instituto Salvadoreño de Protección al Menor.
} 
conflicto con la ley, mejorar sus condiciones de vida, que le propicien con responsabilidad el espacio para su desarrollo social y emocional necesario que garantice sus derechos. Al proceso de reinserción/inserción social de favorecer serie de fortalezas y oportunidades que faciliten el logro de metas.

Las fortalezas identificadas son las siguientes:

- Creación de instancias de coordinación: Comité del Menor Infractor, Subcomité Reinserción Social.

- Especialización en el tratamiento-abordaje de la infancia-juventud.

- Apoyo e interés de la comunidad Internacional.

- Desarrollo de atención multidisciplinaria.

- Instituciones gubernamentales y no gubernamentales (ONG's) comprometidas con la infancia y la juventud.

- Un marco normativo adecuado.

- Surgimiento de redes de apoyo a la infancia y juventud (inicio del proceso).

- Existencia de un organismo de atención a la infancia: ISPM.

- Capacitación-Formación constante de los operadores del sistema (proceso inicial).

- Crecimiento de las personas-profesionales que participan en el proceso.

- Nueva visión de la administración de justicia.

- Existencia de la Escuela de Capacitación Judicial.

- Producción académica.

Entre las oportunidades identificadas encontramos:

- Despenalización de problemas sociales.

- A mayores logros mayor apoyo de la comunidad internacional.

- Predisposición a la coordinación: interinstitucional; multidisciplinaria.

- Hay condiciones para optimizar su eficacia (tendencia).

- Lograr incidencia en los presupuestos nacionales para las políticas de infancia- jóvenes. 
- Independencia de organismos internacionales.

- Descentralización del poder central hacia lo local: Alcaldías.

- Poder de ejecución-gestión.

- Poder presupuestario.

- Poder normativo.

- Despolitización del tema de la niñez-juventud a partir del reconocimiento de sus derechos (alcaldías).

- Descentralización regional de los servicios del ISPM.

- Plan nacional del Consejo de Seguridad Pública.

- Sistema de información de justicia juvenil.

- Demanda para la formulación de política nacional de la niñez.

- Momento de sensibilización de los medios de comunicación al tema. Ej.: Código de ética.

Sin embargo, también es importante reconocer las debilidades en torno al procedimiento. Estas son:

- Insuficiencia y poco impacto de programas de prevención de la delincuencia.

- Insuficientes espacios laborales, educativos, vocacionales, recreativos y culturales.

- Falta una sistematización interinstitucional para la evaluación de la evolución del nuevo proceso de menores.

- No asumen responsablemente el cometido institucional.

- Esfuerzos dispersos y sub-utilización de recursos existentes.

- Duplicado de esfuerzos.

- Se carece de un centro especializado para darle seguimiento a los casos de libertad asistida.

- Inexistencia de centros de desintoxicación, prevención y seguimiento.

- Falta de una política integral.

- Falta de seguimiento a los menores donde cesa el proceso.

- Falta de apoyo y voluntad en la empresa privada.

- Escasez de recursos especializados en la rama de menores.

- Escasez de recursos materiales y financieros. 
- Carencia de un centro especializado para darle seguimiento a los casos de libertad asistida.

- Carencia de un proceso de reinserción social.

- Falta de un programa de protección a testigos y víctimas.

- Abusos de autoridad.

- No hay cultura de denuncia.

- No se integra a los jóvenes en las iniciativas y programas de esa competencia.

- Inexistencia de centros especializados en áreas de atención psicológica- psiquiátrica-médica.

- Inexistencia de centros de desintoxicación.

- Dependencia internacional que frena la autonomía.

- Protagonismo profesional e institucional; y constante incriminación entre instituciones.

- La privación de la libertad no es excepcional, existen abusos.

- Implemento de decisiones administrativas sin evaluación.

- Fuga de personal especializado (fiscalía); y falta de continuidad en el proceso judicial.

- Irrespeto hacia el cumplimiento de la ley (procuraduría).

- Falta de comunicación y coordinación interinstitucional; y de verdaderas figuras de mediación.

- Falta una visión compartida entre instituciones (cada etapa aislada).

- Desperdicio del recurso calificado en actividades administrativas y no en el menor.

- Por otro lado, el proceso de reinserción/inserción social se ve amenazado por:

- Impunidad, frustración, ocio (incremento de agresividad y violencia), reincidencia

- Transculturación a través de modelos negativos

- Carácter marginal del tema "menores" dentro de la agenda nacional, o politización del mismo

- No funciona la política criminal del ministerio correspondiente

- Atención a personas que son deportadas y pertenecen a maras o pandillas 
- Falta de participación del Ministerio de Educación

- Manejo negativo de la opinión pública (manipulación de casos particulares)

- Delincuencia no se interpreta como producto de la violencia, no se ve el trasfondo

- Estigmatización del joven en conflicto con la ley; e inexistencia de programas de divulgación

- Incremento de miembros de pandillas

- Aprobación de la Ley de Armas

- Falta de programas de intervención en crisis

- Efectos negativos de las políticas económicas; y políticas sociales ineficaces

\section{Caracterización del estado actual de los programas}

El estado actual de los programas de inserción y reinserción social puede definirse a partir de los siguientes factores:

- En El Salvador existe un sistema de justicia juvenil incipiente, sin embargo se caracteriza por la ausencia de un sistema interinstitucional de reinserción social.

- No existe una visión compartida de los operadores del sistema y social, así como falta voluntad política de cara a los programas de reinserción.

- No existe incidencia pública, ni fomento de la cultura de paz y de la educación de la población para la prevención de la delincuencia y la reinserción.

- Distribución no equitativa del presupuesto institucional.

- Deficiencias organizativas, comunicaciones y de cooperación en el sistema.

Los factores mencionados influyen en la institucionalización de la violencia. Tomando en consideración esos factores, nos preguntamos: ¿Qué tenemos? ¿qué queremos? ¿qué podemos? ¿qué debemos? Respondiendo a la primera interrogante, tenemos:

- Instancias, personas, experiencias que generan un proceso educativo y de capacitación incipiente. 
- El deseo y la voluntad parta trabajar en beneficio de los jóvenes. Experiencias de trabajo.

- Existencia de esfuerzos (desorganizados, aislados) en el área de inserción social.

- Alto numero de jóvenes sin oportunidades.

- Existencia de ONG's y OG's que traban con la niñez y la adolescencia, con la cuales se ha establecido en alguna medida redes.

- Un sistema moderno de administración de justicia especializado en menores con equipos multidisciplinarios y la coparticipación institucional.

- Iniciativas dispersas de atención a la niñez y la juventud.

- Recursos humanos y materiales e instituciones comprometidas.

- Buena voluntad y la oportunidad de hacerlo.

Lo que queremos lograr es lo siguiente:

- Brindar a la juventud la oportunidad de logar un desarrollo humano justo; y que se ofrezca a la niñez y a la juventud la oportunidad real de ejercer sus derechos.

- Proceso educativo integral que permita al joven lograr su identidad propia, y asumir su responsabilidad, para poder reinsertarse socialmente.

- Política de derechos humanos, de prevención, atención e inserción-reinserción, que garantice el desarrollo las(os) niñas(os), adolescentes y jóvenes como plenos ciudadanas(os).

- Programas y proyectos integrales de reinserción e inserción a las familias y comunidades.

- Constituirnos en una instancia multisectorial e interdisciplinaria a nivel nacional, que emane líneas de acción para la atención y prevención de la violencia y delincuencia juvenil.

- Un proceso de menores que garantice la adecuada formación integral de los jóvenes para una verdadera reinserción social.

- Un verdadero proceso de reinserción e inserción.

- Un sistema nacional de atención a la infancia y juventud; y programas re- educativos en libertad. 
Entendemos que en la actualidad podemos:

- Mejorar los canales de comunicación para conocer el accionar de cada institución y evitar duplicidad de esfuerzos para una mayor agilización del proceso.

- Formular un proceso de inserción social para jóvenes en conflicto con la ley.

- Mejorar modelos mentales a nivel personal e institucional.

- Fortalecer el proceso educativo a partir de sumar los esfuerzos del sistemas.

- Clarificar y objetivizar los factores que inciden sobre la niñezjuventud para diseñar políticas, programas y proyectos adecuados y eficaces.

- Organizarnos, coordinarnos, ser afirmativos y proactivos en el quehacer de cada organismo del sistema.

Existen también áreas de las que debemos ocuparnos como son:

- Crear políticas sociales adecuadas.

- Plantear un modelo de política de la niñez y juventud integrando lo términos de un desarrollo humano sostenible y comprometido a la erradicación de la pobreza, violencia y segregación.

- Sensibilizar-concientizar de los derechos de los niños-jóvenes.

- Crear procesos educativos con enfoque en derechos no asistencialistas.

- Adoptar una actitud afirmativa y proactiva, evitando el protagonismo personal e institucional en beneficio del proceso mismo.

- Trabajar coordinadamente en función de un objetivo común: velar por el interés superior del menor.

- Impulsar acciones para la creación y ejecución de políticas de atención a la infancia y juventud.

\section{Prevención vs. curación}

El cuestionamiento principal es el porque esperar que la niña, el niño y adolescente lleguen a la institucionalización para poder brindarle la protección necesaria que garanticen de alguna manera los derechos que como personas le correspondan. Las razones son 
muchas pero hay una muy poderosa: "la indiferencia" hacia los fenómenos sociales que obligan al sector más vulnerable de la población a sufrir todo tipo de vejámenes; a las que son sometidos por la ausencia de democracia en las políticas orientadas a crear justicia social.

Esa indiferencia que no permite ver que hay hogares donde día a día se lucha por lograr una familia cada vez más estable y unida; escuelas en donde los salones de clases hay estudiantes que verdaderamente han entendido el valor de la educación y por ello se esmeran en ser mejor cada día; en los hospitales pacientes que luchan para que la enfermedad no los logre vencer; en las instituciones de servicio como lo es el Instituto de Protección al Menor en donde la población interna integrada por niña, niño, y adolescente, esperan una respuesta institucional favorecedora que haga prevalecer de nuevo sus derechos, hasta lograr hacer de ellos ciudadanos capaces de ser útiles a la patria que les vio nacer.

A la indiferencia como mal social se une la influencia de la modernización, dirigidos a exigir el menor esfuerzo, a restar importancia a las prioridades; a lo planificado dando rienda suelta al activismo, que cada vez más disminuye el interés en alcanzar las más altas metas y los más nobles objetivos; importando poco o nada la satisfacción personal por el deber cumplido.

La instituticionalización de la niña, niño, y adolescente como mandato asignado por las distintas leyes antes determinados casos, debe estar orientada a la educación y formación de la personalidad del niño; a inculcar normas y valores que garanticen la convivencia social y el respecto a los demás; orientado a desarrollar la responsabilidad, la organización el orden; a enseñarles a responder a metas; a planificar su vida, a tomar decisiones, a tener iniciativa; a educarse hacia la sexualidad y reproducción con responsabilidad; al respecto mutuo y a compartir derechos como también obligaciones, con el propósito de que sean capaces de enfrentar los retos y desafíos del desarrollo. Sin embargo para poder lograrlo todos los autores principales y estratégicos que intervienen en el proceso de atención, juegan el papal mas importante debiendo practicar la perseverancia, profesionalismo, sentido común y la sensibilidad; pero ante todo el amor al prójimo como mandato divino, por lo que no basta ser religiosa/o si está muy lejos de practicarlo. Juega también un papel determinante el instinto maternal que se desarrolla por ese don divino dado por Dios "El ser madre Biológica", solo 
echando mano de este dote de cualidades o características innatas o aprendidas y no fingidas en nuestro quehacer diario lograremos los grandes objetivos de la política nacional de atención a la niñez y adolescencia.

Se necesita, además, despojarse de ciertos paradigmas que nos prejuician y hacen ver a la niñez en riesgo social, como una subespecie de la humanidad, a veces encantadora y otras veces exasperante pero en todo caso desconcertante, sin tomar en cuenta que en esta etapa de la vida del niño (de imitación) esta expuesto al determinismo de sus impulsos, frustraciones y conflictos que dejan huellas muy marcada. Por eso el entorno social y/o familiar en el que se desenvuelven debe de ser de contenido pedagógico constructivo, ya que los niñas/os se identifican fácilmente con las ideas de sus mayores y las interiorizan. Durante esta etapa denominada de imitación son sumamente importantes los modelos; las reglas son básicas pero el ejemplo es el mejor estímulo, lo que significa que si a un niño se le da buena instrucción, pero se le da mal ejemplo, es como darle con una mano alimento y con la otra veneno.

En este proceso evolutivo de la persona, el más complejo es el período de la adolescencia que comprende el de la pre-adolescencia o pubertad con mayor incidencia lo orgánico y lo fisiológico. Sin embargo, en la adolescencia prevalecen más los fenómenos psicológicos que requieren de una adecuada comprensión, ya que algunos comprometen la seguridad del niño, su futuro y las relaciones familiares. Por lo tanto, hay que entender que la adolescencia significa cambios biológicos, morfológicos y psicológicos especialmente en lo afectivo.

El joven como tan presenta inestabilidad, timidez, agresión, insolencia, preocupación y ansiedad. El adolescente cuestiona los valores éticos, estéticos y normativos dando la falsa imagen de rebeldía estructurada, inmoralidad, irrespeto a la autoridad familiar, escolar y social. Presentando desacato a los buenos modales en el trato y presentación personal, por eso se le denomina la edad de la inspiración, porque el adolescente se inspira en grandes ideas cualquiera que sea la índole de estas; necesita héroes y heroínas, si no los tiene los busca; si no lo inspiran los buenos lo harán los malos. Los jóvenes necesitan participar en discusión de aspectos de la vida, pero sobre todo necesitan sentir confianza, amor, comprensión y que se le dé el espacio que le corresponde, puesto que son personas de desarrollo y permanente cambio hasta que adquieren la madurez, 
por lo tanto hay que reconocer que las niñas/os y adolescentes son ciudadanos con derechos prevalecientes y prioritarios que requieren del respecto de su interés superior, contemplado en Código de Familia e interpretado en todo aquello que favorezca su desarrollo físico, psicológico, moral y social para el logro del pleno y armonioso desenvolvimiento de su personalidad. Este es su contrato social y cuanto este se rompe se ve violentado en sus derechos.

Por lo que la prevención comienza desde los primeros años de vida: en la familia, en el jardín de infantes; en un hogar sustituto, etc. Donde quiera que sea no hay que esperar a que llegue a determinada edad, porque para luego es tarde y hasta imposible querer romper esquemas ya formados. iCOMENCEMOS AHORA! 